\title{
An Action Research Approach to Profile an Occupational Therapy Vocational Rehabilitation Service in Public Healthcare
}

\author{
Hester van Biljon, B Occ Ther (UFS), M Occ Ther (UFS) \\ Private practitioner at Work-link Vocational Rehabilitation practice, PhD candidate, University of the Witwatersrand, Faculty of \\ Health Sciences, School of Therapeutic Sciences, Occupational Therapy Department
}

\section{Daleen Casteleijn, B Occ Ther (Pret), B Occ Ther (Hons)(Medunsa), Dip Voc Rehab (Pret), DHETP (Pret), M Occ Ther (Pret), PhD (Pret)}

Associate Professor, University of the Witwatersrand, Faculty of Health Sciences, School of Therapeutic Sciences, Occupational Therapy Department

\section{Sanetta H.J. du Toit, B Occ Ther (UFS), M Occ Ther (UFS), M.Sc. Occ Ther (University of Exeter, UK), PhD (UFS) \\ Affiliated lecturer, University of the Free State, Department of Occupational Therapy; Lecturer, University of Sydney, Faculty of Health Sciences, Discipline of Occupational Therapy}

\section{Simon Rabothata, BOT (Medunsa), Dip Voc Rehab (Pret)}

Assistant Director, Theraputic and Medical Support Services, Gauteng Department of Health

The need for occupational therapists to profile their vocational rehabilitation services, initiated an action research project, within a PhD study. The PhD study was aimed at transforming vocational rehabilitation services in occupational therapy departments in Gauteng public healthcare through action research. The aim of the project was to develop a tool that would allow occupational therapists doing vocational rehabilitation, to systematically and comprehensively profile their services. The profile tool could be used for practice reflection, research, to assist with planning, policy making and/or quality management. It will be used in the final phase of the PhD study to allow for critical reflection on vocational rehabilitation practice transformation in Gauteng public healthcare.

The profile tool was designed and developed during action research cycles in public healthcare vocational rehabilitation units. It was refined through further action research cycles with occupational therapists that offer vocational rehabilitation services in Gauteng's public healthcare. The service profiles generated from these cycles were presented for participant validation. The final profile tool was sent for critical appraisal to a panel of experts acting as 'critical friends'.

The processes of designing, developing, refining, validating and disseminating the tool are presented in this article as a contribution to the practice of vocational rehabilitation and to conclude the dissemination outcome of action research.

Key words: occupational therapy, vocational rehabilitation services, public healthcare, action research, profile tool

\section{INTRODUCTION}

\section{Background}

Vocational rehabilitation is a multi-professional service provided to individuals of working age with health-related impairments, limitations or restrictions within work functioning. The primary aim of such a service is to optimise work participation in spite of illness or activity limitations'. In occupational therapy, concern with functional ability and purposeful activity are unique features ${ }^{2}$ that allow the profession an important place in vocational rehabilitation practice ${ }^{3}$. An effective occupational therapy vocational rehabilitation service assists the transition between injury, illness, impairment, disability and return to optimal functional ability in a work sphere. It bridges the gap between health institutions, which are usually the point of entry for an injured or sick worker, and the labour market ${ }^{4}$.

South Africa's Gauteng province has a high demand for vocational rehabilitation services. It is the hub of the country's commerce and industry. Home to $30 \%$ of South Africa's (SA) total population, its age distribution shows that $73 \%$ of this population is of working age $^{5}$. In South Africa, $68 \%$ of the population depend entirely on public healthcare ${ }^{6}$. The effect of no or poor vocational rehabilita- tion in public healthcare is obvious in a commerce and industry driven province such as Gauteng, with a high prevalence of injury at work, crime and motor vehicle related injury, the impact of Aids and pressure to return to work as quickly and effectively as possible.

In the National Health Amendment Bill debate on the 14 August 2012 Dr Aaron Motsoaledi, South Africa's Minister of Health said: "The deteriorating quality of healthcare in our public hospitals has been a thorn in the flesh of our country for quite some time"" . Occupational therapy services within public healthcare are included in this and services that require specialised knowledge and experience, like vocational rehabilitation are most affected. A Vocational Rehabilitation Task Team (VRTT) was convened, in 2010 in Gauteng with the aim of resuscitating the province's vocational rehabilitation services. The VRTT is a group of occupational therapists, working in Gauteng's public healthcare sector and concerned with occupational therapy vocational rehabilitation services in the province. In 2013 the first author, a PhD candidate from the University of the Witwatersrand, joined the group with the research aim of transforming occupational therapy vocational rehabilitation services in Gauteng through action research.

In keeping with the cyclical nature of action research (i.e. ob- 
serve, plan, act and reflect) ${ }^{7}$ the first phase of the $\mathrm{PhD}$. research was to observe and ask: 'What is going on in occupational therapy vocational rehabilitation services in Gauteng's public healthcare?' If occupational therapists were able to subjectively compile a comprehensive and accurate profile of their own vocational rehabilitation service, their insight and understanding could be a transformative agent for service development. A comprehensive service profile drawn up at the beginning of a research intervention could also be used to compare with a service profile at the end of the intervention. This could allow objective macro post-reflexivity to answer the question: 'What was the impact of action research on occupational therapy vocational rehabilitation services in Gauteng's public healthcare?'

Searching for a means to profile a vocational rehabilitation services in public healthcare left the researcher with insight into the importance as well as the problems of service measurement ${ }^{8}$. Selecting an appropriate method to facilitate a collaborative approach with occupational therapists working in the services was an important point of departure. Audits, quality surveillances or observation style inspections are easily interpreted as judgmental and could exaggerate power relations which prohibit the emancipatory effects of action research'. The first author wished to engage in a profile process that would not only support practice development but actively involve practitioners in the process. She opted for action research methodology as it provided the cooperative development of a non-threating and non-invasive tool. A tool that therapists could potentially use to profile their vocational rehabilitation services at a certain point in time. Such a profile would allow them to critically reflect on their practice and identify areas that needed improvement and thus it holds the potential to transform a vocational rehabilitation service.

It was decided to develop the tool through action research cycles within and with the population it would be used for ${ }^{10}$. This tool would be designed and developed by gathering data from multiple sources and in different ways about all aspects of vocational rehabilitation by occupational therapists considered to be experts in the field. Practitioners were incorporated as fellow researchers in the refining and validation of the tool. This allowed them to experience ownership of the tool, the service profiles generated by the tool and by extension the actions that would follow to improve and transform their vocational rehabilitation practices" ${ }^{\prime \prime}$.

The aim of this article is to describe the process and outcome of designing, developing, refining, validating and disseminating a tool that occupational therapists working in public healthcare can use to profile their vocational rehabilitation services.

\section{LITERATURE REVIEW}

The four sources from literature that principally influenced the development of this profile tool were Donabedian's work ${ }^{8,13-14}$ the Gauteng Department of Health's 'Allied Health Care Professionals Standards and Audit Tools' ${ }^{15,16}$; and research by Buys ${ }^{17}$ and Beukes $^{3}$. Various other frameworks and bodies of knowledge measure healthcare outcomes ${ }^{18-23}$, but the selected sources best embodied the purpose and context for which the profile tool was developed. Mant ${ }^{24}$, commenting on performance indicators in assessing quality of healthcare, states that the context and purpose in which indicators are used should be considered. He cautions that using only an outcome measure as performance indicator is a mis-demeanor. He feels that outcome measures only focus on the impact of therapy but do not consider lifestyle and socio-economic factors (as vocational rehabilitation services do).

Donabedian developed a model in the 1960's that provided a framework for examining healthcare services and evaluating quality of healthcare that is still widely recognised and referred to. The model has three categories: structure (the context in which healthcare is delivered), process (the sum of all actions that make up healthcare) and outcome (the effects of healthcare on patients and relevant communities) $)^{8}$. Donabedian developed his model to be flexible enough for application in diverse healthcare settings and at various levels of service delivery ${ }^{12}$. He perceived healthcare as consisting of technical tasks, interpersonal exchange and amenities of care (the circumstances under which the task is performed) and that the quality of healthcare in practice was the product of these factors. He felt that every form of interaction in a healthcare setting is "the measure of the humanity and dignity of us all"14:248. This resonates well with action research methodology and the service occupational therapists render within the field of vocational rehabilitation.

Occupational therapists working in Gauteng's public healthcare identified a need to implement standards for the profession in public healthcare and developed an audit tool for this purpose ${ }^{16}$, of which a section was published in 2006. The Gauteng Department of Health's 'Allied Health Care Professionals Standards and Audit Tools (Hospital)' is for use in occupational therapy, physiotherapy, speech therapy and audiology and social work professions and acknowledges Donabedian's work. It comprises four audit tools; the environment, equipment and facilities audit tool; the client record keeping tool; the management audit tool; and the client satisfaction audit tool. The Head of Departments are meant to ensure that these audits are done at least once a year, summarised, compliance and non-compliance areas identified with a work plan attached and submitted to a profession specific quality assurance coordinator in head office. At present there is a $75 \%$ submission compliance rate. The results of the audits are used as a management tool to improve service delivery. To ensure compliance, the head office staff conduct random spot clinical audits ${ }^{15}$.

Several authors in South African literature provide valuable contributions to vocational rehabilitation services in terms of professional competences, quality and standards of service. Buys ${ }^{17}$ identified 16 professional competencies required by occupational therapists who deliver vocational rehabilitation services in South Africa. Beukes ${ }^{3}$, developed a standard statement and measurement criteria for an effective and efficient occupational therapy service, regarding the assessment of work abilities (vocational assessment). Robinson ${ }^{25}$ notes that setting standards from within a profession is fundamentally positive, as standards will be relevant, achievable and realistic if set by those who understand the challenge and emphasis of the profession. She also notes that occupational therapists often work in relative isolation both in government and in private practice and that these practitioners may find it more difficult to implement quality measurement, improvement or management techniques.

'Batho Pele' (People First) is a South Africa initiative to improve the quality, accessibility, efficiency and accountability of service delivery in the public sector ${ }^{26}$. The National Health Insurance (NHI) was launched to ensure that everyone living in South Africa gets access to quality healthcare, regardless of their socio-economic status $^{27}$. The research method and aim of this study are in line with these initiatives.

\section{METHOD}

\section{Study design}

Action research phenomenology forms the basis of this study and a multi-collaborative and interpretivist action research approach was used ${ }^{28,29}$. Action research is practice based and done by people who want to find out more about their practice with the view of improving $i^{30}$. It places practitioners at the center of an enquiry ${ }^{31}$ allowing them to be fellow researchers and participants, learning from their experiences and producing knowledge that is relevant to their practice situations and to which they can relate ${ }^{32}$. Action research is an emancipatory intervention that brings about shared responsibility and open accountability ${ }^{33}$. Reason and Bradbury ${ }^{34}$, and Reason ${ }^{35}$ offer three strategies of action research practice; first-person action research which is a personal inquiry approach, second-person action research which is an ability to inquire face-to-face with others into issues of mutual concern and third-person practice which aims to extend the research to a wider community of enquiry. They suggest 
that the most compelling and enduring kind of action research will engage all three strategies, as this study does.

Critical reflection is an essential component of action research ${ }^{36}$. It brings about the conscious questioning of practice ${ }^{35}$, a collective analysis of action ${ }^{37}$ and allows enquiry that leads to learning ${ }^{32}$. In so doing it contributes to personal and professional development and improvement ${ }^{30}$. This critical reflection can be done individually or as a group with the distinguishing factor being to change practice ${ }^{38}$. McNiff ${ }^{30: 33}$ notes that "Action researchers are real-life people who wish to investigate their practices and offer explanations for what they are doing so they can show how they hold themselves publically accountable".

\section{Population}

Dick" uses the term 'stakeholders' in action research to describe the population. He describes stakeholders as persons who have a stake in a programme and who are affected by or able to affect practical change.

In this research the first author, applying first-person action research, researched and designed a concept profile tool (see step I).

There were two developing stakeholders: The first and fourth authors, using second-person action research, developed the profile tool through several action research cycles at four academic hospitals in Gauteng where vocational rehabilitation services are offered. They were also the field researchers and acted as catalysts, informed observers ${ }^{32}$ and data collectors throughout the research process (see step 2).

There were 127 refining-stakeholders involved as third-person researchers. They were occupational therapists working in Gauteng's public healthcare, who were interested in and/or offered vocational rehabilitation, were invited to host workshops called 'Profiling a Vocational Rehabilitation Service' within their practices. The first author presented three workshops as action research cycles and the tool was refined during each cycle. (see step 3).

There were two groups of validation stakeholders:

The refined profile tool and the service profiles that resulted from the developmental and refining cycles were presented to the vocational rehabilitation task team (VRTT) of Gauteng. They critically reflected on the tool and provided participant validation of the practice profiles (see step 4).

A group of 39 pre-selected vocational rehabilitation experts were identified by the authors for use as 'critical friends'. In action research the concept of 'critical friends' is used to indicate stakeholders who are invested in the field of knowledge and can offer objective and expert feedback ${ }^{39}$. The criteria for inclusion into this group were occupational therapists with previous experience of working in South Africa's public healthcare and current experience of more than five years of working in and/or teaching vocational rehabilitation. The refined profile tool was sent to them for critical reflection (see step 4).

All participants were informed verbally and by a written pamphlet that they could keep, that this project was part of a larger PhD study. How this project fitted into the study was explained, how the generated knowledge will be used was discussed and consent forms were signed. The $\mathrm{PhD}$ research had university and hospital clearance.

\section{Data gathering}

Throughout the research, data were gathered in the form of field notes, reflective journaling, critical reflection, written and verbal feedback from stakeholders and experts.

\section{The process}

There were five steps to the research: the designing, the development, the refining, the validation and the dissemination of the profile tool.

Step I: (See Figure I) The designing of the profile tool was done by the first author, engaging in first-person action research. A systematic search and study of literature relevant to objective observation of occupational therapy and vocational rehabilitation services was done. This included; audits, models, frameworks and instruments concerned with quality control, practice standards, service and outcome measurement tools and performance indicators. Four sources as discussed above were identified ${ }^{3,13,15,17}$ to be relevant to the context and methodology. Donabedian's framework ${ }^{13}$ was chosen to guide the systematic plotting of all elements of occupational therapy vocational rehabilitation services within the three categories of structure, process and outcome. The elements were compiled based on information from competencies identified by Buys ${ }^{17}$; suggestions by Beukes ${ }^{3}$; the Gauteng Department of Health's standards and audit tool ${ }^{15}$; and the first author's 20 years' experience in the field of vocational rehabilitation. Confirmation and expansion of these elements were supplemented through additional (verbal and electronic) discussions with Buys, Beukes, some of the authors of the Gauteng standards and audit tool and in consultation with colleagues of the first author who have experience in vocational rehabilitation. A concept profile tool with three parts, namely the structure, the process and an outcome was designed.

Continuous first-person action research cycles were used throughout the designing stage. The first author reflected on the need and circumstances for the use of a profile tool, all available information was gathered and considered; a draft tool was drawn up and critically reflected on through continuous action research cycles until the tool was to the satisfaction of the first author. Reflective journaling was done throughout this stage. In the final cycle of the design step journaling guided planning, of the next step of the tool development.

Step 2: The profile tool was developed during four action research cycles. The first and fourth author, using second-person action research, put the concept profile tool through an action

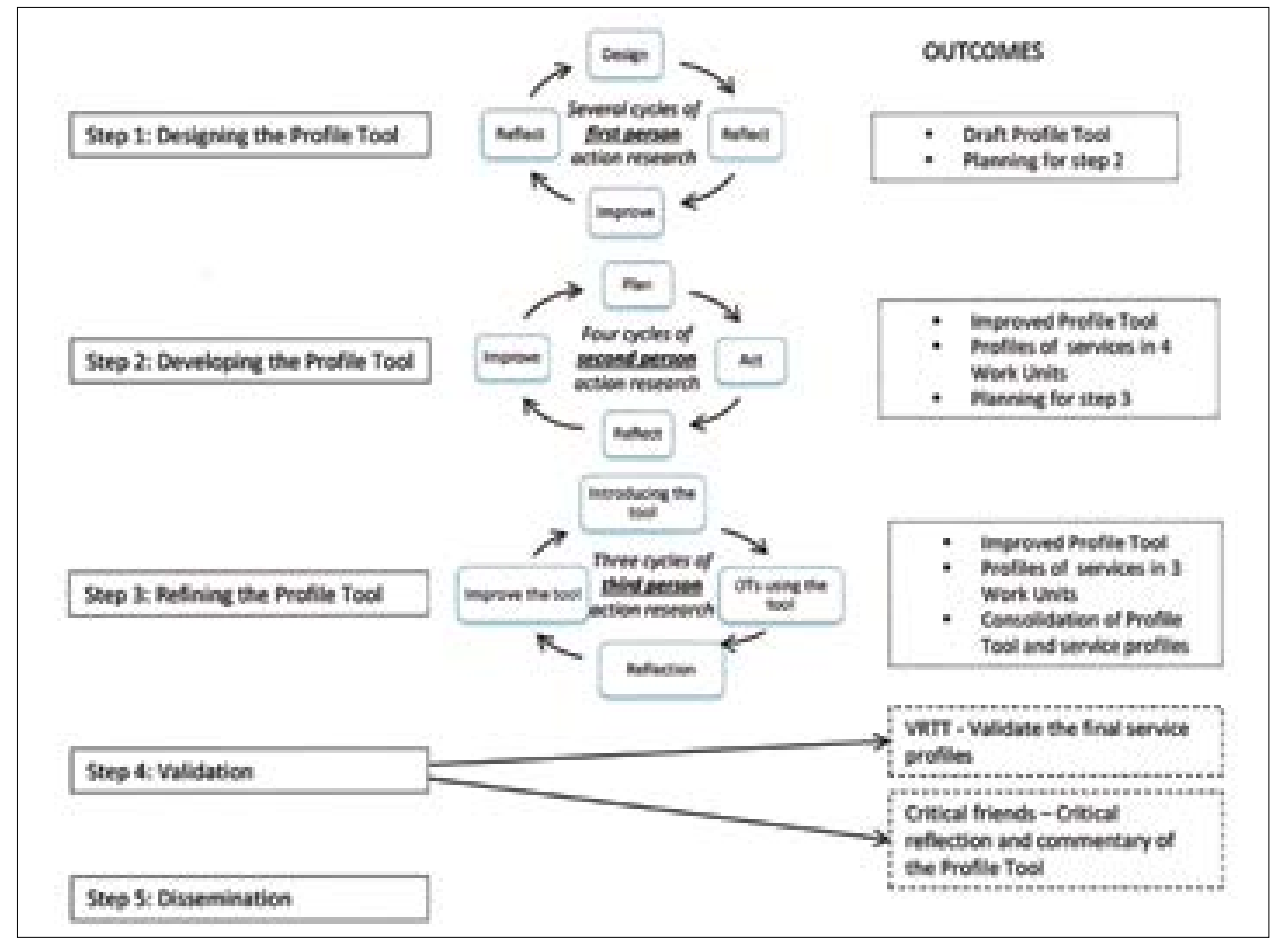

Figure I: A graphical representation of the five research steps 
research cycle at each of the four academic hospitals in Gauteng that offer vocational rehabilitation services.

The authors planned unannounced visits during working hours, to the four academic hospitals in Gauteng who had occupational therapy departments with work units. Working in the area where the vocational rehabilitation services were offered the tool was used separately by each author to profile the service. Field notes were kept. Reflective journaling done separately by each author was completed post profiling, while still on the premises. This was followed by a face-to-face critical reflection, discussing their findings and experiences with each other. Specific attention was paid to the design and content of the tool, improving and changing it for the next visit. The final step of the visit was to compile an agreed upon profile of the visited vocational rehabilitation service. In this way their collective experience, skills and knowledge contributed towards improving the tool and compiling a profile of the vocational rehabilitation service offered.

After each cycle the first author studied the field notes and reflective journals, made the necessary changes to the profile tool, sorted, saved and stored all data. Additional ideas or comments between the visits were shared electronically between the first and fourth authors and changes incorporated as necessary. Each new cycle thus started with an improved profile tool.

Step 3: To refine the profile tool a workshop introducing the profile tool with a practical session of applying and critically reflecting on it, was planned and presented by the first author. The workshop was for any clinical occupational therapists interested in vocational rehabilitation. The third-person research aims of the workshops were to incorporate the wider community of clinical occupational therapy practitioners in Gauteng's public healthcare as partners in the development of the tool and to expand and authenticate the vocational rehabilitation service profiles that emerged from the developmental step.

An invitation to host the workshop within their practices was extended to the four academic hospitals in Gauteng who had been used for the development of the profile tool. They were requested to invite all occupational therapists in their departments and surrounding hospitals and clinics that referred clients and made use of the specialised vocational rehabilitation equipment and services offered at the hosting hospital.

Each workshop was presented in the form of an action cycle. Firstly, the profile tool was introduced by providing the background and contextual information. Participants then used the profile tool, applying it specifically to their vocational rehabilitation services, while maintaining an open dialogue on an individual and/or group basis with the presenter. They then divided into small groups to critically reflect and discuss the design and use of the tool as well as the service profiles that were generated by the use of the tool. They were asked to consider how its use and results could impact on their vocational rehabilitation practices. Verbal feedback from each group was provided. The workshop concluded with anonymous individual critical reflection on the workshop and the tool forms.

The expected outcome of the workshop was to enable clinical occupational therapists to profile their vocational rehabilitation services which holds practical, theoretical and research value. Implementing a comprehensive and contextually relevant profile tool that effectively indicates what a vocational rehabilitation service looks like, and/or should look like, would be helpful to occupational therapists that are offering, or wish to offer, vocational rehabilitation services in public healthcare. The profile tool could also be used for research, to assist with planning and policy making and quality management of occupational therapy vocational rehabilitation services. The workshop was registered and accredited with the Health Professions Council of South Africa's (HPCSA) continuing professional development units.

After each workshop the first author analysed and sorted the contributions, feedback and information. The tool was revised and improved before presentation at the next workshops. Information was added to expand the vocational rehabilitation service profiles of the hospitals that were developed during step two. These profiles were used in the next step.

Step 4: The validation of the profile tool was done in two sections. The vocational rehabilitation service profiles that emerged from the development and refining steps of the research were presented to the VRTT for validation, by the first and fourth authors. The therapist(s) received the profile of the hospital she/ he was working in and was given 30 minutes to study it and ask questions if necessary. The instruction was to provide comments and participant validation of the profile handed to them. This was collected in the form of written comments, reflective journaling, verbal interaction with the primary and/or secondary author and general discussion in the group.

To further validate and enrich the credibility of the profile tool it was sent for objective critical appraisal and expert opinion to a panel of pre-selected 'critical friends'. The selection criteria for these critical friends were that they should be South African occupational therapists that had experience of working in public healthcare and had more than five years of current experience in vocational rehabilitation. The experts were sent electronic formats of the tool and asked to consider it, use it and comment on it within two weeks.

All data from this step were considered, reflected on and selected changes were made to the tool.

Step 5: The final step of dissemination of the tool was undertaken. The VRTT decided that the profile tool would be taught at the annual vocational rehabilitation orientation workshop, an event attended by newly appointed occupational therapists to Gauteng's public healthcare. The first author made an electronic format of the tool available to share with any interested occupational therapists working in vocational rehabilitation. The fourth author introduced the tool to all occupational therapists working in Gauteng public healthcare through official public healthcare forums. The development process and tool content are intended for publication in the form of a scientific paper to a South African peer reviewed journal with national and international circulation.

\section{Data analysis}

The field notes, reflective journaling, written and verbal feedback from the workshops and from the experts were systematically analysed by the researcher through thematic and discourse analysis. In keeping with good research practice and in support of action research principles ${ }^{32,40}$, thematic analysis of the raw data was manually analysed immediately after gathering. Data were summarised and categorised. These thematic summaries influenced the next action research phase.

'Authentic voices' ${ }^{41}$ used in this article will be indicated as FN for field notes, RJ for reflective journaling, CR for critical reflection, WFS for written feedback from stakeholders, VFS for verbal feedback from stakeholders, WFE for written feedback from experts and VFE for verbal feedback from experts acting as critical friends.

\section{RESULTS}

In step one the tool was designed using first-person action research strategy. Through several action research cycles the first author continuously reflected on her actions and incorporated new information into the development of the concept profile tool.

"This tool must have a variety of data capturing methods like listing, interviews, sliding scales, photos. Like Donabedian says ${ }^{42}$ - variety should give better validity." (RJ)

"I wish I had something like this when I was a young OT, I would have gotten the bigger picture instead of getting bogged down with the small stuff." and "It (the tool) must be easy to understand and use so the most inexperienced occupational therapist can use and benefit from it." (RJ)

During step one a technical action research process directed the initial design of the tool. The first author was instrumental in 
designing the draft format of the tool and prepared it for the action research process engaged in during step two.

In step two the visits to vocational rehabilitation services at four academic hospitals and the use of the tool in these services brought development of the tool through using second-person action research strategies. Areas identified for changes related to the duplication of data gathered; ambiguous instructions; and time concerns. Therefore the tool had to be simplified, shortened and language and grammatical errors addressed. The time it took to administer the profile tool depended on the size and extent of the vocational rehabilitation service as well as familiarity with the tool. The times varied between two to five hours. The action research cycles of implementing the tool and reflecting on it provided a profile of each service. Simultaneously the profile tool emerged as a standardised instrument.

"What we have with this tool is the ideal vocational rehabilitation service. It will be nice to use as a measurement in future." (FN)

"We must not immobilise a service with paperwork. The core business of therapists is to see patients." (RJ)

It was decided to get clinical occupational therapists to use it and in so doing incorporate their feedback into the development of the tool and existing profiles. The planning of a workshop ensued; it was registered with the Health Professional Council of South Africa (HPCSA) as an approved continued professional development (CPD) activity and marketed to occupational therapists at the four academic hospitals.

The workshops offered in step three were to refine the tool and include additional aspects to the profile, using third-person action research strategy. Three of the four academic hospitals in Gauteng who had been used for the development of the profile tool accepted the invitation. The fourth hospital declined the invitation, stating that their occupational therapists were not interested in vocational rehabilitation.

Overall the feedback from therapists participating in the workshops was that they enjoyed an opportunity to use the tool and apply it to their own situations. They felt this offered them the opportunity to reflect and discuss specific aspects of the service and to plan and set goals. They also enjoyed discussing their practice with the researcher and their peers, valuing the impartial feedback. The primary contribution of the workshop was that it captured an authentic picture of the challenges and concerns clinical occupational therapists on grassroots level experienced. For example:

"You cannot use part two (process profiling) if you do not know vocational rehabilitation and understand the aspect of a vocational rehabilitation service and some of us were not trained sufficiently in vocational rehabilitation." (WFS)

In step four the validation of the tool was undertaken. The profiles of the vocational rehabilitation services that emerged in step two and three were consolidated into a single profile of each hospitals vocational rehabilitation service. At a VRTT meeting occupational therapists familiar with a relevant profile contributed to the validation of its authenticity. Discussion in the group and individual written feedback showed that all profiles were accepted to be true reflections of the services being offered. The group discussion and written feedback also reflected a dimension of greater transparency in the group.

"Now that we know what the problems are we can work together to fix them and need not worry about trying to keep up a front." (WFS)

Reflection on the profile tool itself showed that they felt the first part (structure profile) is long and tedious and the second part (process profile) was more enjoyable to complete. The outcome profile instigated an animated discussion. There were strong feelings expressed regarding the absence of student training, marketing of services, research and publication.

"It is impossible to get ethical clearance to do research if you are a clinician and there is nobody to help you or give advice if you find yourself stuck. The only way you can do research as a clinician is if you enroll for a university post grad degree or course and why should we do that! It will not affect our promotion or our salary and nobody has time." VFS

"You put hours and hours of work into it (writing a journal article) and then it's not good enough. We don't really know what we are doing anyway. It is easier to write for the FOCUS (newsletter) but can that be considered publication?" (VFS)

"This is just about it. This shows exactly what our problem is; we have the motivation but not the know-how." (WFS)

Very few changes were suggested for the tool content and layout. It appeared as if the group lacked confidence and expressed that their opinions on the tool might not be "good enough". They suggested that it be sent to 'academics' to take a look at it. Suggestions of sending it to a panel of experts were unanimously supported.

The tool was sent to 39 critical friends for critical appraisal and expert opinion. Thirteen of them responded within the requested timeframe. Changes suggested were grammatical in nature and no shortfalls were identified. A critical friend in a private vocational rehabilitation practice noted: "It makes you realise that in private practice we run assessment units and not a vocational rehabilitation service." (WFE)

A critical friend in a public healthcare management position from another province indicated:

"We need this kind of tool to critically evaluate and improve our (vocational rehabilitation) services in public healthcare. Thank you to everyone in Gauteng for all the hard work and sharing it with us."

The fifth and final step of dissemination then followed. As a result interest and enquiries into the tool were received from the provinces of KwaZulu Natal, Free State and the Western Cape.

\section{Summary of the content of the finalised profile tool}

The Vocational Rehabilitation Profile Tool is written in easy to understand English so that therapists of all levels of experience could find it accessible and useful. It consists of four sections; an introduction, structure profiling, process profiling and outcome profiling. The time it takes to complete the tool will be influenced by the size of the work practice. It should take two to five hours to complete the tool for the first time. Thereafter an occupational therapist familiar with the tool and the work unit would take less than an hour to update and expand it.

The introductory section is four pages long. It includes a cover letter written in a personal tone suggesting why occupational therapists might consider using the profile tool to reflect on and enhance their vocational rehabilitation practices. They are asked to use the tool and send suggestions, ideas and questions to the author so that the tool can continue evolving and maintain relevance. Contact details for such feedback are provided. Background and general information on the research and reason for the development of the tool is given. A discussion on how to use the tool and suggestions on what to do with the information generated from the profile follows. It concludes with references, recommended reading and the last review date.

The structure profiling section (see Table I) enquires about the context within which vocational rehabilitation services are offered. These include resources available, accessibility to the service, appearance of the area, tests tools and activities available, staff, managerial and maintenance support for the service.

The process profiling section (see Figure 2) enquires about the occupational therapy practice of vocational rehabilitation and the scope of the service occupational therapists offered. It works on the premise that in their vocational rehabilitation service, occupational therapists offer prevention of injury and awareness of good practice programmes; screening and assessment of functional ability; various forms of intervention; involvement in the placement of persons with injuries/disabilities into open, sheltered, protected and other alternatives in the labour market; and offer follow-up services. Investigation of these services is done in the form of sliding scales and comments. 
Table I: A section from the Structure Profiling - An investigation of resources available to the vocational rehabilitation service

\begin{tabular}{|l|l|}
\hline 6. Resources to support the Vocational Rehabilitation Service \\
\hline $\begin{array}{l}\text { Are the following resources } \\
\text { available to the Vocational } \\
\text { Rehabilitation Service? }\end{array}$ & Describe and discuss \\
\hline $\begin{array}{l}\text { Social work services } \\
\text { (For referral of social intervention, } \\
\text { grants etc.) }\end{array}$ & \\
\hline $\begin{array}{l}\text { Referral resources for skills devel- } \\
\text { opment, (Training facilities etc.) }\end{array}$ & \\
\hline $\begin{array}{l}\text { Open labour market placement } \\
\text { support } \\
\text { (Placement or personnel agencies } \\
\text { etc.) }\end{array}$ & \\
\hline $\begin{array}{l}\text { Alternative placement options } \\
\text { and support. (Sheltered/protected } \\
\text { workshops, self-employment.) }\end{array}$ & \\
\hline $\begin{array}{l}\text { Motor vehicle driving assessment } \\
\text { and adaptations/customisation. }\end{array}$ & \\
\hline Other & \\
\hline
\end{tabular}

\section{Intervention}

3.I Are work visits being done as part of the vocational rehabilitation service?

\begin{tabular}{|c|}
\hline None is begin done \\
comprehensive service.
\end{tabular}

3.2 Are there work-hardening, work-readiness, conditioning and return to work programs offered?

\begin{tabular}{|c|}
\hline None is being done \\
comprehensive services
\end{tabular}

3.3 Are there job-seeker programs and related support?

\begin{tabular}{|c|}
\hline None is offered \\
comprehensive programs exists \\
\hline
\end{tabular}

3.4 Are there pre-vocational skills training programs and support offered?

\begin{tabular}{|c|c|}
\hline $\begin{array}{c}\text { No such programs } \\
\text { exists }\end{array}$ & $\begin{array}{c}\text { Excellent and } \\
\text { comprehensive programs exists }\end{array}$ \\
\hline
\end{tabular}

3.5 Are occupational therapists trained, mentored and supported in such programs?

\begin{tabular}{|c|c|}
\hline $\begin{array}{c}\text { No training/ mentoring } \\
\text { support is provided }\end{array}$ & $\begin{array}{c}\text { Excellent comprehensive } \\
\text { training/mentoring/ } \\
\text { support exists }\end{array}$ \\
\hline
\end{tabular}

Discuss and describe your opinions:

Figure 2: A section from the Process Profiling - An investigation of the intervention aspect of the vocational rehabilitation service

The outcome profiling section (see Table $I I$ ) enquires about the effect of the services offered. Service outcomes that were identified to be indicators of a matured and comprehensive occupational therapy vocational rehabilitation service are: general awareness of
Table II: A section from the Outcome Profiling - An investigation of student training in the vocational rehabilitation service

\section{Student training}

Are there any undergraduates and/or post-graduate students being trained in the Vocational Rehabilitation Services? Yes/No

\begin{tabular}{|l|l|}
\hline \multicolumn{1}{|c|}{ If 'Yes': } & \multicolumn{1}{|c|}{ Answers and Comments } \\
\hline $\begin{array}{l}\text { From which } \\
\text { institution? } \\
\text { How many are } \\
\text { undergraduates and } \\
\text { how many are post- } \\
\text { graduates? }\end{array}$ & \\
\hline $\begin{array}{l}\text { How many students } \\
\text { does the service have } \\
\text { in a year? }\end{array}$ & \\
\hline $\begin{array}{l}\text { How often does the } \\
\text { service have students } \\
\text { in a year? }\end{array}$ & \\
\hline $\begin{array}{l}\text { How long are they } \\
\text { here at a time? }\end{array}$ & \\
\hline Who supervises them? & \\
\hline If 'No': Why not? & \\
\hline
\end{tabular}

the services, user satisfaction, student training, research, publication, statistics and future plans of the service and auto-reputation. Autoreputation being a form of self-evaluation described by Donabedian ${ }^{13}$.

\section{DISCUSSION}

The notion of profiling is to record and analyse the current status of services in a non-judgmental, objective manner. Donabedian suggests that in studies of quality one needs to ask 'What goes on here?" rather than "What is wrong?" $13: 721$. The profile tool offers public healthcare occupational therapy vocational rehabilitation practitioners a structured and systematic observation of their practice. It gives them information that they gather themselves to critically reflect on their practices to manage, plan and improve their vocational rehabilitation service, using a tool they were instrumental in developing. In addition the tool and resulting profiles will be used in further research aimed at improving vocational rehabilitation services in these practices. It will also be used to measure the effectiveness of the research intervention at the conclusion of the research.

In action research the researcher is considered an equal partner within a team, contributing knowledge and/or experience and acting as a catalyst in addressing practical problems ${ }^{36}$. Action research is also essentially practitioner and practice-based research ${ }^{35}$ and focuses on change and participation as an interactive form of knowledge development ${ }^{43}$. The cyclical process of continuous and structured planning, action and reflection characterise action research ${ }^{30,43}$. Incorporating these elements in the design, development and refining of the profile tool was brought about in a manner sensitive to context and perspectives of those directly involved ${ }^{28}$. In addition the potential benefits of participant empowerment and accountability ${ }^{44}$ were incorporated.

As with all tools the question of standardisation and validation arises $^{25}$. Literature showed that 'standardisation' is a term generically used by occupational therapists when discussing validity and reliability features of test and tools. Shenton ${ }^{45}$ describes the use of all the above terms as 'positivist terminology' and propagates the use of Guba's constructs and terminology ${ }^{46}$ for discussions of rigour in qualitative research (such as action research). Guba addresses criteria that ensure trustworthiness/ rigour similar to that pursued by positivists but compatible to qualitative research ${ }^{46}$. This paper chooses to align itself with this and use the word 'trustworthiness' to indicate the generic use of standardisation, 'credibility' in preference to internal validity, 'transfer- 
ability' in preference to external validity, 'dependability' in preference to reliability and 'conformability' in preference to objectivity ${ }^{45}$.

The following criteria of trustworthiness were addressed during the development of the profile tool:

The credibility of the tool (i.e. Does the profile tool measure/ show what it is intended to show?) was considered and addressed. Participant validation of the ensuing profiles was done. A variety of data collection methods and overlapping methods and data sources were used with the generating of the tool and designed in the administration of the tool itself. The intention was to obtain peer scrutiny through critical appraisal of experts and publication in a peer reviewed journal. The background, experience and qualifications of the authors qualify them as experienced practitioners in occupational therapy, vocational rehabilitation and tool development.

The transferability and generalisability of the tool (i.e. To what degree can the tool be applied to other situations?) is affected by the methodology used. The critique that the knowledge generated by action research is generalisable only within the context of the research population ${ }^{28}$ is noted by the authors. The tool is restricted for use in vocational rehabilitation practices for occupational therapists. Within this practice context the authors believe that the tool is generic enough to hold potential for use in vocational rehabilitation services outside of the public healthcare setting in which it was developed. The dissemination of the findings of this research was done within the South African context as it could be of interest to occupational therapists who are interested in vocational rehabilitation or practice in similar contexts. The process of generating the profile tool could be useful at local or international level for those who wish to apply the ideas and findings within similar contexts or to replicate the study.

The dependability of the tool (i.e. Would similar results be found if it was used by different occupational therapists?) was attended to by using simplified instructions and offering workshops where therapists were introduced and instructed in tool use. The tool went through design, development and refinement phases and was practically implemented by a variety of therapists during several action research cycles. Participant validation of the resulting profiles showed no dispute of the resulting practice profile.

The conformability of the tool (i.e. What efforts towards objectivity and restriction of researcher bias are in place?) was attended to through purposeful transparency. Critical reflection is a key element that defines action research ${ }^{36}$ and an openness to feedback from 'critical friends' enhances the conformability of the research ${ }^{47}$. In this research it was applied throughout the action research cycles and enhanced with participant validation, constantly inviting peer review and experts' critical appraisal. The knowledge generated through action research has to be fed back to the participants ${ }^{28}$ and made public as this constitutes its characteristics of being scrutinisable ${ }^{32}$ which is encapsulated in the dissemination of the development of the tool.

The profile tool has not been in use outside of the developmental stage and the authors acknowledge that many of its trustworthiness characteristics will only come to light once it is being used extensively and in different contexts. Use in different contexts would stimulate further research and strategies aimed at testing the trustworthiness.

We do believe that although developed within a public healthcare context and for specific research purposes it has the potential for more extensive use. The authors would like to encourage colleagues to use the profile tool, test it, improve it and expand its usefulness by sharing their findings on public forums. The hope is that eventually the tool can be used in vocational rehabilitation services to help therapists do quality management and provide information for planning and policy making. Tool dissemination could also raise an awareness of the scope of vocational rehabilitation services that occupational therapists can offer as so many practices are doing only the assessment aspect of vocational rehabilitation ${ }^{48}$.

Donabedian has contributed significantly to strategies for quality of healthcare but his work is not without criticism. Carayon et al ${ }^{49}$ and Coyle and Battles ${ }^{50}$ caution that using the sequential progression from structure to process to outcome is too linear a framework and limits the understanding of how the three aspects influence each other. They propose that users acquire an understanding of how the three aspects of service influence and interact with each other and with such consideration use them in varying orders as circumstances dictate. They also criticise the model for failing to incorporate antecedent characteristics e.g. environmental factors, cultural, belief and attitudinal influences. All of which are important precursors to quality, especially in a South African situation.

\section{CONCLUSION}

The ultimate aim of healthcare work is to enhance the quality of provision for the users ${ }^{28}$. Managing and addressing the quality of service in public healthcare is an international and ongoing concern ${ }^{51}$. In South Africa there are accreditation committees, national care standards, audits and guidelines in place to address the quality of service in public healthcare ${ }^{55,52,53}$. All of them were developed and function externally to the practice setting they hope to improve and are not service specific. The authors have the experience and are of the opinion that it is very difficult to address the standard of a service by 'remote control'. By sharing the process of development of a tool that profiles a vocational rehabilitation service using action research allowing scrutiny, peer review and inviting feedback, authenticity is demonstrated which are important aspects of rigour in action research ${ }^{28,32}$.

Action research allowed the practitioners offering the service to be part of the process of developing a tool they can use to profile the services they offer. Being able to profile a vocational rehabilitation service holds practical, theoretical and research benefits. Having a comprehensive and contextually relevant tool that effectively indicates what a vocational rehabilitation service looks like, and/or should look like, will be helpful to occupational therapists that are offering, or wish to offer, vocational rehabilitation services in public healthcare as well as in private practices. This allows them to set goals and develop their practices in a systematic and mindful manner.

Donabedian, citing various studies to support his opinion, states that people are good judges of the effectiveness of the organisations in which they work ${ }^{13}$ and the services they render. Allowing occupational therapists to measure their own services within certain guided constructs brings about the action research benefits of identifying and owning the problem ${ }^{28}$ which in most cases leads to the motivation to look for solutions of practice problems.

\section{ACKNOWLEDGEMENTS}

The management of Steve Biko Academic Hospital (Pretoria), Dr George Mukhari Academic Hospital (Ga-Rangkuwa), Charlotte Maxeke Academic Johannesburg Hospital (Johannesburg), Chris Hani Barawanath Hospital (Soweto) for allowing us to develop the tool in their work units.

All the occupational therapists that took part in the profiling a vocational rehabilitation service workshops and contributed to the refining of the tool.

Members of the Vocational Rehabilitation Task Team, Gauteng: Naazneen Ebrahim, Lynn Soulsby, Mashudu Mphohoni, Ashley Magner, Claudette Parkinson, Catherine Couvaras, Buhle Mkhize who were part of the validation of the tool and for their constant support and encouragement.

The experts acting as critical friends who responded and contributed towards this research: Derryn Brummer, Janine Schoeman, Megan Townshend, Rene Walker, Julie Whitlock, Ann Nott, CarolLynn Stirrat, Lee Randall, Daleen du Plessis Venter, Keshika Naidoo, Rugpath Jayanthi, Dilnaaz Khan, Tharina Annandale.

The first author would like to acknowledge the 2013 Faculty Development Grant from the University of the Witwatersrand.

\section{REFERENCES}

I. Escorpizo R, Ekholm J, Gmünder H, Cieza A, Kostanjsek N, Stucki G. Developing a Core Set to Describe Functioning in Vocational Rehabilitation Using The International Classification of Functioning, 
Disability, and Health (ICF). Journal of Occupational Rehabilitation, 2010; 20(4): 502-II.

2. Reed K, Sanderson S. Concepts of Occupational Therapy: Lippincott Williams \& Wilkinson, 1999.

3. Beukes S. The Accreditation of Vocational Assessment Areas: Proposed Standard Statement and Measurement Criteria. South African Journal of Occupational Therapy, 20I I; 4I (3): 42-9.

4. Buys T, van Biljon H. Occupational Therapy in Occupational Health and Safety: Dealing with Disability in the Work Place. Occupational Health, 1998; 4(5).

5. Lehohla P. Census 20II, 03-0I-42. Pretoria: $201 \mathrm{I}$

6. Ataguba JEaA, J. Health care financing in South Africa: moving towards universal coverage. CME, 20I0; 28(2): 74-8.

7. Thom A. Healthcare needs surgery if $\mathrm{NHI}$ is to work. Mail\&Guardian, 2012 I2 to 18 October;Sect. Health.

8. Donabedian A. An Introduction to Quality Assurance in Health Care. Ist Edition ed. New York, NY: Oxford University Press, 2003.

9. du Toit S, Wilkinson A. Research and Reflection: Potential Impact on the Professional Development of Undergraduate Occupational Therapy Students. Springer Science + Business Media, 20 I 0; 23(Systematic Practical Action Research): 387-404. Epub 5 February 2010.

10. Campbell E, Delong J, Griffin C, Whitehead J. Introduction to Living Theory Action Research in a Culture of Inquiry Transform Learning in Elementary, High School and Post-graduate Settings. Education Journal of Living Theories, 2013; 6(2): I-II.

II. Dick B. Entry and Contracting. Action research and evaluation on-line. Australia: www.aral.com.au/areol; 2013.

12. Donabedian A. The Role of Outcome in Quality Assessment and Assurance. QRB Qual Rev Bull, 1992; I8(II): 356-60.

13. Donabedian A. Evaluating the Quality of Medical Care. The Milbank Quarterly, 2005; 83(4): 691-729.

14. Donabedian A. Quality Assurance in Health Care:Consumers' Role. St Catherine's College, Oxford: Quality in Health Care; 1992. p. 247-5I.

15. Gauteng Department of Health. Allied Health Care Professionals Standards and Audit Tools (Hospital), Gauteng Province, Pretoria: 2013

16. Foote $\mathrm{H}$, Lamont $\mathrm{S}$, Burger $\mathrm{E}$, Leishman $\mathrm{A}$. The Introduction of a Quality Assurance Programme in Gauteng Health Hospital Occupational Therapy Services. South African Journal of Occupational Therapy, 2006; 36(I): 6-10.

17. Buys TL. Professional Competencies Required by Occupational Therapists Delivering Work Practice Services to Workers with Disabilities in the South African Open Labour Market. Pretoria: University of Pretoria; 2006.

18. Restall G, Ripat J, Stern M. A Framework of Strategies for ClientCentred Practice. Canadian Journal of Occupational Therapy, 2003; 70(2): 103-12.

19. Restall G, Ripat J. Applicability and Clinical Utility of the ClientCentred Strategies Framework. Canadian Journal of Occupational Therapy, 2008; 75 (5): 288-300.

20. American Occupational Therapy Association. Occupational Therapy Practice Framework: Domain \& Process 2nd Edition. American Journal of Occupational Therapy, 2008; 62(6): 625-83.

21. Casteleijn D. Stepping Stones from Input to Outcomes: An Occupational Perspective. South African Journal of Occupational Therapy, 20I3; 43(I): 2-9.

22. Campbell SM, Roland MO, Buetow SA. Defining quality of care. Social Science \& Medicine, 2000; 5 I (I I): 16I I-25.

23. Arah OA, Westert GP, Hurst J, Klazing NS. A Conceptual Framework for the OECD Health Care Quality Indicators Project. Int ] Qual Health Care, 2006; I8(I): 5-13.

24. Mant J. Process Versus Outcome Indicators in the Assessment of Quality in Healthcare. International Journal of Quality in Heath Care, 200I; I3(6): 475-80.

25. Robinson H, Botha A. Quality Management in Occupational Therapy. South African Journal of Occupational Therapy, 2013; 43(3): 8-18.

26. Sogoni M. Address by the Honourable Mbulelo Sogoni, Premier of the Eastern Cape. Batho Pele learning network November 2008; Port Elizabeth2008.

27. Mataboge M. Polokwane resolution \#8: National health insurance. Mail and Guardian. 2012.

28. Koshy E, Koshy V, Waterman H. Action Research in Healthcare. London: SAGE Publications, 2011.
29. Whitelaw S, Beattie A, Balogh R, Watson J. A Review of the Nature of Action Research, (2003).

30. McNiff J. Action research for professional development. Concise advice for new and experienced action researchers. Dorset: September Books, 2010.

31. McNiff J, Whitehead J. All you need to know about Action Research London: SAGE Publications, 2006.

32. Zuber-Skerritt O. Action Learning and Action Research. Songlines through Interviews. Rotterdam, Netherlands: Sense Publishers, 2009.

33. Cohen L, Manion L, Morrison K. Research Methods in Education 5th Edition. London Routledge Falmer, 2000.

34. Reason PAB, Bradbury H. The SAGE Handbook of Action Research Participative Inquiry and Practice University of Bath, UK: SAGE Publications Ltd 2008.

35. Reason PAB. Handbook of Action Research. London: SAGE Publications Ltd, 2007.

36. Dick B. Action Research and Evaluation On-line Course. Australia: www.aral.com.au/areol; 2013.

37. Kemmis S, McTaggart R. Strategies of Qualitative Inquiry, Third Edition. Denzin N, Lincoln Y, editors2007.

38. Denzin NK, Lincoln YS. Strategies of Qualitative Inquiry: SAGE Publication, 2007.

39. Costa A, Kallick B. Through the lens of a critical friend. Educational Leadership, 1993; 5 I (2): 49-5I.

40. Creswell J. Qualitative inquiry and research design (2nd ed). CA Sage: Thousand Oaks, 2007.

41. Pearson A. Balancing the evidence:incorporating the synthesis of qualitative data into systematic reviews. JBI Reports, 2004; 2: 45 - 64.

42. Donabedian A. The Definition of Quality and Approaches to its Assessment Health Administration Press, 1980.

43. Maree K. First Steps in Research. Revised 4th Impression ed. Pretoria: van Schaik, 2010.

44. Johns C. Becoming a Reflective Practitioner. Edition n, editor. Oxford: Blackwell Publishing, 2007.

45. Shenton AK. Strategies for Ensuring Trustworthiness in Qualitative Research Projects. Education for Information, 2004; 22(IOS Press): 63-75. Epub 6 January 2004.

46. Guba EG. Criteria for Assessing the Trustworthiness of Naturalistic Inquiries. Educational Communication and Technology Journal, I98I; 29(2): 75-91.

47. Zuber-Skerritt O. A Model of Values and Actions for Personal Knowledge Management Journal of Workplace Learning, 2005; I7(I): 49-64.

48. van Biljon HM. Occupational Therapists in Medico-Legal Work South African Experiences and Opinions. South African Journal of Occupational Therapy, 2013; 43(2): 27-33.

49. Carayon P, Schoofs Hundt A, Karsh B-T, Gurses AP, Alvarado C], Smith $M$, et al. Work system design for patient safety: the SEIPS model. Quality and Safety in Health Care, 2006; I5(I): 50-8.

50. Coyle YM, Battles JB. Using antecedents of medical care to develop valid quality of care measures. International Society for Quality in Health Care, 1999; I I(I): 5-I2.

5I. Lindenauer PK, Remus D, Roman S, Rothberg MB, Benjamin EM, $\mathrm{Ma} A$, et al. Public Reporting and Pay for Performance in Hospital Quality Improvement. N Engl | Med, 2007; 356: 486-96.

52. Burger E. Allied Health care Professionals Standards and Audit Tools (Hospital), Johannesburg: 2013

53. Reporter S. Health minister's audit to usher in new NHI pilot era. Mail \& Guardian. 20I I;Sect. National News.

\section{Corresponding Author}

Hester van Biljon

vanbiljon@mjvn.co.za

PO Box 830,

Auckland Park, 2006

Johannesburg 